\title{
NOTAS SOBRE OS IMIGRANTES PORTUGUESES NO BRASIL * (Sécs. XIX e XX)
}

\author{
Maria Luisa Nabinger de Almeida Pasckes
}

\begin{abstract}
RESUMO - A imigração portuguesa para o Brasil, no final do século XIX, foi uma consequência da transiçâo política e econômica do fím do século. O sistema de "remessa" de contingentes foi um recurso usado para satisfazer interesses duplos. De um lado, aliviava a tensâo causada por grupos que queriam deixar Portugal; de outro, facilitava o equilíbrio interno. Neste quadro, o Brasil era evidencialo como lugar ideal para imigraçâo. $O$ fato de ser um país rico, em desenvolvinnento, ter a língua, tradições e instituições portuguesas, facilitava aos interessados.
\end{abstract}

\section{Introdução}

A História Contemporânea portuguesa é entre nós pouco conhecida. Em geral, ainda não saímos dos tempos das "descobertas marítimas" ou da "colonização portuguesa". Talvez tenhamos principiado o fim deste programa escolar com a "Revolução dos Capitães".

Por outro lado, é necessário ressaltar que a ideologia das "descobertas marítimas" dominou Portugal durante séculos, dificultando ou mascarando o desenvolvimento do capitalismo português (final do Séc. XIX) e tudo aquilo que advém deste novo modo de produção em contraposição ao mercantilismo.

É portanto, dentro do novo contexto português - desenvolvimento das relações de produção capitalista e o aparecimento da classe operária - que podemos situar um "excedente" da mão-de-obra, os emigrantes.

Paralelamente à situação portuguesa, no Brasil e, em particular, em São Paulo, inicia-se a implantação do sistema de parceria pelo Senador Vergueiro, por volta de 1850.

Neste regime, a mão-de-obra imigrante, os colonos, deveriam se tornar pequenos proprietários nas plantações de café. Entretanto, por falta de uma política agrária e ainda pelas ambigüidades da política imigratória nos anos posteriores à abolição da escravidão vamos conhecer o fracasso do sistema de parceria. 
PASCKES, Maria Luisa Nabinger de Almeida. Notas sobre os imigrantes portugueses no Brasil (sécs. XIX e XX).

A tentativa de implantação da pequena propriedade, com a mão-deobra imigrante, ao lado da grande lavoura, com a economia cafeeira para exportação, são políticas contraditórias até 1930 .

Com a Revolução de 1930 no Brasil, surge a preocupação em definir uma política agrária dirigida para o aproveitamento da mão-de-obra nacional. Nasce então, a proibição temporária da imigração em dezembro daquele ano com a justificativa de proteção à mão-de-obra nacional. Os dados estatísticos já indicavam um grande número de desempregados, sobretudo no Rio de Janeiro e em São Paulo. O desemprego atingia também os imigrantes, em particular, os portugueses no então Distrito Federal.

À proibição da imigração segue-se a proibição da saída do ouro, criando para Portugal dificuldades para a sua balança de pagamentos com a falta das remessas dos emigrantes. A transferência de fundos no Brasil ficou posteriormente limitada a 300 mil réis ${ }^{1}$.

Veremos ainda que no caso da imigração portuguesa não se justificava a necessidade de braços para a nossa lavoura cafeeira. Os imigrantes portugueses preferiam o comércio, nos centros urbanos, o Distrito Federal, e só posteriormente chegam na Capital de São Paulo ${ }^{2}$.

\section{A. Razões da Emigração Portuguesa para o Brasil}

\section{Situação econônico-social en Portugal}

De forma breve, o séc. XIX em Portugal foi um período de transição. Ao lado do desenvolvimento do capitalismo comercial e industrial, o país conhecia a crise econômica com a perda do principal mercado, o Brasil, e as dificuldades políticas com a crise da Monarquia.

O desenvolvimento do capitalismo português pode ser observado com a extinção do corporativismo da Idade Média em 1834. De fato, o sistema corporativista medieval impedia o desenvolvimento do próprio capitalismo liberal ${ }^{3}$.

1 Notícias divulgadas pelo "O Estado de São Paulo", dezembro de 1930.

2 "Nảo amamos a terra, amamos a aventura..." - Alexandre de Albuquerque, citado por SILVA ROC.HA, Joaquim đa. História da Colonização do Brasil, R.J., Imprensa Nacional, 1918-1919 (vol. H).

3 É interessante observar que já em 1761 algumas antigas corporaçōes foram extintas na época do Marquês de Pombal. 
Com a separação do trabalhador e os seus meios de produção, tanto no meio rural como nas cidades, sobretudo Porto e Lisboa, cresce o comércio exportador português do vinho e desenvolve-se a indústria têxtil, papel, louças e vidros, entre outros.

A introdução da mecanização na agricultura portuguesa, a exploração das terras incultas, a abolição dos antigos direitos sobre a livre circulaçao de mercadorias, geram um desenvolvimento agrícola com a expansão da viticultura, da criação de gado para a exportação e da cultura do arroz.

As revoltas populares, como a Maria da Fonte e a Patuléia (18461848), refletem as alterações ocorridas nas relações sociais de podução no campo. A economia de subsistência é destruída, ainda que a pequena propriedade não integrada no comércio exportador possa persistir em Trás-os-Montes, Beira Alta e Beira Baixa.

É, portanto, neste contexto econômico que observamos a formação de um "excedente" de mão-de-obra que se deslocará para as grandes cidades, Porto e Lisboa, e para o exterior.

A perda do Brasil significou prejuízo no processo de acumulação português o que, em parte, foi substituído pelo desenvolvimento do comércio exportador.

Mas foram com as remessas dos emigrantes que Portugal conseguiu compor o equilíbrio de sua balança comercial. Logo, a emigração portuguesa passa a ser elemento necessário à solução dos sem trabalho no campo e na cidade, além de contribuir para o equilíbrio da balança comercial ${ }^{4}$.

Também o desenvolvimento do capitalismo comercial e industrial em Portugal provocará a crise ao nível de instituições políticas. A Monarquia se arrastará com as denúncias de submissão ao domínio inglês, desencadeando as primeiras lutas pela implantação da República, o que viria a ocorrer em de 5 outubro de 1910 .

No início do séc. XX, após a $1^{\text {A }}$ Guerra Mundial, a emigração portuguesa aumentara consideravelmente devido à carestia de vida em Portugal e às conturbações políticas em que já estava envolvida a nova República.

$4 \quad$ "O que nos falta é precisamente o capital, e a nossa emigração, longe de desperdiçar e levar para fora, aumenta-o pelas remessas clas suas melhores economias, dando ao nosso depauperado organismo um permanente revigoramento". In: COSTA, Afonso Augusto da - 1871-1937 Estudos da Economia Nacional: o problema da emigraçāo, Lisboa, Imprensa Nacional, 1911, p. 121. 
PASCKES, Maria Luisa Nabinger de Almeida. Notas sobre os imigrantes portugueses no Brasil (sécs. XIX e XX).

Posteriormente, com a economia corporativista de Salazar ${ }^{5}$, a economia portuguesa passa a ser tutelada pelo Estado, sobretudo, através dos Planos de Fomento ${ }^{6}$. Há a partir de então, uma preocupação em organizar-se uma política de emprego. Apesar da emigração não ter cessado, pensamos ter havido uma maior racionalização com relação à emigração do final do séc. XIX.

Os dados sobre a mão-de-obra européia no Brasil de 1820 à 1960, indicam para os imigrantes portugueses:

$1820-1833$ - 13,31\%; $1884-1933$ - 68,39\% e $1934-1960-18,30 \%$.

Vemos que durante os primeiros 13 anos, a emigração portuguesa para o Brasil atingiu $13,31 \%$. No entanto, com relação aos 49 anos seguintes, os dados indicam um aumento da emigração portuguesa de $55,08 \%$. Portanto, um total de $81,7 \%$ de emigrantes portugueses no Brasil durante pouco mais de um século. Do início do período de Salazar até 1960, o Brasil abrigou $18,30 \%$ de imigrantes portugueses. O período de maior imigração foi, portanto, aquele entre 1884-1933.

A diminuição da emigração portuguesa para o Brasil no período Salazarista deve-se então a um maior controle daquela devido ao estabelecimento de uma política de emprego que se manifesta desde o $1^{2}$ Plano de Fomento (1953-1958) e pela mudança nos destinos da emigração ${ }^{7}$.

$\mathrm{Na}$ verdade a economia portuguesa se encontrava num impasse: por um lado, os Planos de Fomento previam sempre a expansão e a modernização técnica na agricultura e na indústria. Por outro, haveria um agravamento no equilíbrio do mercado de trabalho, com o desenvolvimento das forças produtivas. É assim que, a partir do $2^{\circ}$ Plano de Fomento (1959-1964), o governo tentará estabelecer uma política de emprego para sair deste impasse: o equilíbrio do mercado de trabalho seria, portanto, encontrado no crescimento do emprego através da expansão das indústrias e dos serviços. A maior mecani-

5 A Implantaçăo da organização corporativa em 1933 foi inspirada nas mesmas razões que fizeram desaparecer as corporações medievais: num primeiro momento, elas impediam o desenvolvimento da livre concorrência; noutro, elas foram implantaclas com o objetivo de limitar esta mesma concorrência. A organizaçẫo corporativista foi, portanto, uma alternativa ao capitalismo liberal e uma defesa contra o socialismo, de acordo com a conjuntura mundial existente após a $1^{\circ}$ guerra mundial e a crise de 1929.

$6 \quad 1^{2}$ Plano de Fomento - 1953-1958; $2^{2}$ Plano de Fomento - 1959 - 1964; Plano Intercalar - 1965 1967 e $3^{\circ}$ Plano de Fomento - 1968-1973.

7 A partir dos anos 50, os portugueses vão preferir a Venezuela, os EUA, e a Europa (França, Alemanha e Bélgica). 
zação na agricultura também garantiria a mão-de-obra para o setor secundário e resolveria o problema do sub-emprego no campo. A conseqüencia foi uma estimulação indireta para o êxodo rural e à emigração. A "paz social" seria, portanto, encontrada com o equilíbrio interno do mercado de trabalho e a formação de uma reserva de mão-de-obra no exterior.

\section{Importância econômica da emigração para Portugal}

De acordo com os dados estatísticos, sabemos que Portugal durante anos não ultrapassou alguns milhões de habitantes ${ }^{8}$

A emigração portuguesa não foi, portanto, conseqüência de um excesso populacional.

Sabemos ainda que o país não é assim tão pobre como se divulga. Segundo a obra de Gomes Percheiro, Portugal além de ter solo muito fértil, possui também minas de ouro, de ferro, de prata, etc. ${ }^{9}$.

Ora, o que atraía os imigrantes para o Brasil? "A ambição (de ser rico) inconsciente dos imigrantes" 10 .

Naturalmente, isto é uma razão ideológica para explicar a atração pelo Brasil. Na verdade, porém, a questão se coloca na crise econômica que atravessava a Monarquia portuguesa no final do séc. XIX e na política de emprego estabelecida por Salazar posteriormente.

De fato, com a independência do Brasil, Portugal sofreu um profundo abalo no seu sistema mercantilista que repercutiu no seu sistema político. Assim, a emigração através das remessas, foi a única fonte encontrada para que o país pudesse equilibrar seu déficit.

Em 1891, segundo as fontes, a remessa dos imigrantes portugueses no Brasil, atingiam a soma de 14.000 contos de réis por ano ${ }^{11}$.

Na mesma época, segundo Oliveira Martins, as remessas dos imigrantes podiam ser classificadas de três formas: primeiro, os trabalhadores repa-

População do Continente e Ilhas: 1864 - 4.188 .410 hab.; 1911 - 5.960 .056 hab.; 1878 4.550.699 hab.; 1920 - 6.032 .991 hab.; 1890 - 5.049 .729 hab.; 1930 - 6.825 .883 hab.; 1900 5.423.132 hab.; 1942 - 7.702.182 hab. (*) população provável. In: Anuário Demográfico, Lisboa, I.N.E., 1940.

9 Gomes PÉRCHEIRO, D. A. Portugal e Brasil - Emigraçäo e Colonizaçäo (crítica), Lisboa, Typ. Lusp-Hespanhola, 1878, p. 33.

10 Idem, p. 32.

11 OLIVEIRA MARTINS. Jornal do Comércio (de Lisboa), citado por: COSTA, A. A., op. cit., p. $127-128$. 
PASCKES, Maria Luisa Nabinger de Almeida. Notas sobre os imigrantes portugueses no Brasil (sécs. XIX e XX).

triados voltavam com uma soma entre 7.000 e 8.000 contos de réis. Segundo, as rendas anuais de alguns repatriados atingiam 3.000 a 4.000 contos de réis. E finalmente, as remessas feitas para as famílias encuanto pensão, esmolas, presentes, ficavam entre 2.000 e 3.000 contos de réis.

As remessas foram de tal forma importantes que chegavam mesmo a ultrapassar a soma das exportações portuguesas para o Brasil no final do séc. XIX. Enquanto através das remessas Portugal recebia 18.000 contos de réis anuais, pelo comércio exportador, a soma não atingia 4.000 contos de réis anuais $^{12}$.

As economias dos imigrantes portugueses no Brasil tiveram, portanto, grande importância econômica para Portugal na medida em que puderem concorrer para o equilíbrio de sua balança comercial. Esta situação não se alteraria no Salazarismo.

Haveria além disto, o interesse do governo português no final do século XIX e início do séc. XX, em engajar os emigrantes nos centros urbanos no Brasil, uma vez que o setor comercial, por exemplo, oferecia maiores possibilidades de poupança que a agricultura.

O objetivo do governo português foi, portanto, de orientar a emigração para as cidades, Rio de Janeiro e São Paulo, para que eles pudessem desenvolver a atividade comercial em detrimento da atividade agrícola. Isto representaria ainda a possibilidade de maior consumo dos produtos portugueses pelos imigrantes no Brasil ${ }^{13}$. Entendemos assim, porque seria necessário defender a ideologia de que "Portugal não é um país agrícola, nem nós, os portugueses, somos um povo de agricultores" ${ }^{14}$.

\section{O "Eldorado" Brasileiro}

O que atraía os imigantes portugueses para o Brasil? O que desejavam eles fazer num país tão longe? Seguramente a idéia de um "eldorado" brasileiro foi o que mais motivou os portugueses a emigrarem. Aliás, a fantasia de

12 Ibid, p. 127-128.

13 "...o imigrante urbano é melhor cliente do commercio português do que o imigrante rural". In: D'Abreu, Dr. Teixeira - Cambiantes da Emigraçäo Portuguesa, conferência realizada no R.J. em 30/10/1916, S.P., Typ. Ileal, 1917, p. 41. Ver ainda a conferência lida pelo Sr. Carlos de Sampaio Garrido, cônsul português em Sâo Pauto, na secle ch Câmara Portuguesa de Commercio. In: "O Estadinho", 8/12/1919.

14 Alexandre de Albuquerque, citado por: SILVA ROC:HA, Joaquim da, op. cit., p. 302. 
um enriquecimento fácil e uma vida mais opulenta já crescia mesmo na viagem para o Brasil.

Segundo o depoimento de um médico da Junta de Emigração de Portugal $^{\mathrm{r}}$, os emigrantes portugueses deixavam-se iludir sobre seu futuro imediato no Brasil devido às condições de vida, de alimentação e de assistên. cia sanitária por que passavam durante três semanas a bordo de muitos navios que os trazia.

Na medida em que as condições de viagem eram superiores às condiçöes gerais de vida nas aldeias de origem, estes emigrantes experimentavam o sentimento de uma aventura bem sucedida antes mesmo de aqui chegarem. Foi este sentimento que muitas vezes levava os trabalhadores a se amargurarem com a precariedade da vida inicial no Brasil. Imaginamos que tanto a idéia de um enriquecimento no Brasil como o sofrimento saudosista e as dificuldades de adaptação material na chegada estimulavam os imigrantes portugueses a uma dedicação quase integral ao trabalho. Sobretudo se este 1rabalho era por conta própria.

Isto também explica porque os imigrantes se dedicavam mais às atividades urbanas, principalmente o comércio autônomo. É que a lembrança da vida anterior dedicada na maioria dos casos à agricultura, sem criar a possibilidade de garantir a própria subsistência, os trazia ao Brasil para uma atividade que os conduziria a uma ascençâo aos privilégios đe vida.

A escolha do "eldorado" brasileiro é explicada pela identificação, em primeiro lugar, com a língua e certamente pelos conhecimentos das riquezas brasileiras, que entretanto, foram privilégios de alguns portugueses - os colonizadores.

No dizer de um imigrante, no Brasil "a gente não se sente estrangeiro c... todos pensam em voltar. mas voltar rico" ${ }^{16}$.

Dentre as "causas (ideológicas) prováveis da emigração", segundo a publicação no I.N.E. ${ }^{17}$, o "desejo de melhorar de fortuna" era o que mais prevaleeia nos 17.547 emigrantes de um total de 20.772 emigrantes do Reino em 1901.

Para o Brasil. de um total de 14.559 emigrantes naquele ano, 12.434 vinham com o "desejo de melhorar de fortuna". Para as outras causas, classificadas cono "outras e desconhecidas", somente 2.125 emigrantes.

15 "En conversa com um mético da Junta de Emigrậ̣̂ de Portugat". In: "O' Estado de Sĩo Pau$10 ", s / 6 / 1954$.

16 "Neste diílogo, o retrato di colónia", In: "O Estack de Sî̀ Paulo", 10/07/1969.

17 "Emigraçio Portuguesa", Lisboa, 1.N.E., 1901. 
PASC:KES, Maria Luisa Nabinger de Almeida. Notas sobre os imigrantes portugueses no Brasil (sécs. XIX e XX).

Em $1901^{18}$, portanto, $70,1 \%$ da emigração portuguesa vinha para o Brasil e $85,4 \%$ destes emigrantes visavam melhorar de fortuna, ou seja, ficarem ricos.

B. Caracterização Sócio-Econômica dos Emigrantes Portugueses

\section{Procedência}

De uma população em torno de 5 milhões de habitantes no final do século XIX, Portugal nos enviou mais ou menos 300.000 trabalhadores, ou seja, $6 \%$ de sua população total ${ }^{19}$.

Segundo a publicação do I.N.E. ${ }^{20}$, da região de Trás-os-Montes vieram $14,5 \%$ de emigrantes de Bragança e Vila Real.

Da região do Minho, vieram 13\% de emigrantes das cidades de Viana do Castelo e Braga.

Em torno da cidade do Porto, a região do Douro Litoral, partiram 17\%.

Da região de Beira Litoral, deixaram as cidades de Aveiro e Coimbra, $25 \%$ de emigrantes.

Em seguida, da região de Beira Alta, que atinge as cidades de Viseu e Guarda, tivemos $22,6 \%$ da imigração.

Da cidade de Castelo Branco saíram $0,5 \%$ de trabalhadores da região de Beira Baixa.

Do litoral, das cidades de Leiria e Lisboa, vieram $6,3 \%$ de emigrantes para o Brasil.

No interior, da cidade de Santarém, na região de Ribatejo, partiram $0,5 \%$.

Da região do Alto Alentejo, as cidades de Portalegre e de Évora, nos enviaram $0,1 \%$.

18 Infelizmente só dispomos destes dackos para aquele ano. De qualquer forma, eles são significativos na medicta em que representam o perf́odo de maior imigração portuguesa no Brasil.

19 É preciso observar que os dactos estatísticos sobre a emigração portuguesa não sẫo sempre precisos. Existem grandes diferenças entre as estatísticas portuguesas e as brasileiras. Além disto, devido aos critérios seguidos por estes governos, às vezes não encontramos indicação para alguns anos do final do séc. XIX. Nossos clados são, portanto, um ć́lculo aproximaclo a partir de diversos outros.

20 EVANGeliSTA, João. Um Século de Populaçảo Portuguesa - (1864-1960), Lisboa, I.N.E. 1971 (publicaçâo do Centro de Estudos Demográficos). 
Finalmente, no sul, das regiões do Baixo Tejo e do Algarve, partiram 0,6\% da cidade de Beja, enquanto que de Faro saíram 0,4\% de trabalhadores, respectivamente.

De acordo com os dados acima, vemos que a maioria dos imigrantes portugueses no Brasil vieram das regiões onde os setores de produção mais importantes eram o comércio exportador e a pequena agricultura. Da Beira Litoral, Beira Alta, Douro Litoral, Trás-os-Montes, Minho e Estremadura vieram $98,7 \%$ de emigrantes portugueses para o Brasil durante o final do século XIX.

Em seguida, das regiões do Baixo Tejo, do Ribatejo, Beira Baixa, Algarve e Alto Alentejo, vieram 2,1\% de emigrantes para o Brasil no mesmo período. O que demonstra ser insignificante a contribuição do sul de Portugal na imigração brasileira.

Durante os primeiros anos do séc. XX até $1920^{21}$, a procedência dos emigrantes para o Brasil conhece alterações. É da região de Trás-os-Montes, com $90 \%$ que chegam a maior parte dos trabalhadores, seguidos por outras regiões do norte de Portugal. Aumentando, porém a emigração das regiões do Ribatejo e do Baixo Alentejo.

A partir de 1930, houve uma diminuição da emigração portuguesa para o Brasil em todas as regiões. Somente a região de Trás-os-Montes mantém sua contribuição com $87,3 \%$. As demais, Beira Alta e Beira Litoral permanecem também acima de $80 \%$.

Entre $50 \%$ e $80 \%$ de emigrantes portugueses para o Brasil, situam-se às regióes do Minho e Douro Litoral.

Nas regiões meridionais houve maior declínio da emigração, sobretudo, no Alto Alentejo e no Algarve.

Para os anos a partir de 1940 continuam sendo as regiões do norte de Portugal que mais contribuem na emigração para o Brasil: mais de $90 \%$ de Trás-os-Montes.

Entre $80 \%$ e $90 \%$ seguem-se as regiões do Minho, Douro Litoral e Beira Litoral.

Entre $70 \%$ e $80 \%$ saem da região de Beira Baixa, Ribatejo e Estremadura. É do Algarve ainda a menor contribuição de emigrantes para o Brasil neste período.

21 Nossos dados para este periódico são ainda precários. Foram baseados em EVANGELISTA, João, op. cit. 
PASCKES, Maria Luisa Nabinger de Aimeida. Notas sobre os imigrantes portugueses no Brasil (sécs. XIX e XX).

Durante a década de 1950, as regióes que mais contribuem com a imigração no Brasil, são as de Trás-os-Montes e Beira Alta, com mais de 90\%. Seguidas pelas regióes do Minho, Douro Litoral, e Beira Litoral, com $70 \%$ e $80 \%$.

Das regiões do Ribatejo, Estremadura e Alto Alentejo, saem entre 50\% e $70 \%$ de emigrantes para o Brasil. Permanecem as regiōes do Baixo Alentejo e do Algarve com menos de $50 \%$.

Nos anos de 1960 existem ainda algumas oscilações entre as regióes de procedência dos imigrantes portugueses no Brasil. Entretanto, permanecem como dominantes as regiôes de Trás-os-Montes, Beira Alta e Douro Litoral.

De maneira geral, podemos concluir que desde o final do séc. XIX até 1960, a maior parte dos imigrantes portugueses no Brasil são oriundos das regiöes da parte norte de Portugal, sobretudo, Beira Alta (Viseu), Beira Litoral (Aveiro e Coimbra) e Trás-os-Montes (Bragança e Vila Real).

\section{Ocupação Econômica em Portugal}

Apesar da fata de dados precisos sobre os setores de produção nos quais os imigrantes portugueses eram ligados no seu país de origem, podemos entretanto, fazer nossa análise baseada nas percentagens indicadas pela publicação do I.N.E. ${ }^{22}$.

Assim, no que concerne às atividades econômicas dos imigrantes em Portugal, vemos que eles são, principalmente, ligados ao setor agrícola, no final do séc. XIX, ou seja, $45 \%$.

Os empregados do comércio e os comerciantes são em torno de $19 \%$.

Os trabalhadores da construçäo civil, inclusive carpinteiros e pedreiros, são em torno de $4,5 \%$.

No setor de "ocupações domésticas", temos 1,5\% de emigrantes.

Em "outras ocupações" os dados alcançam $14 \%$ e que englobam os pescadores, alfaiates e cabeleireiros.

Finalmente, as ocupações desconhecidas são em torno de $25 \%$.

Esta situação pouco se modificaria no decorrer do séc. XX. Apenas, a partir de 1950 o Brasil começa a receber também trabalhadores qualificados. 


\section{Ocupação Econômica no Brasil 23 .}

No Brasil a maior parte dos imigrantes portugueses localizam-se principalmente no Rio de Janeiro. Em São Paulo, eles só começam a chegar mais para o final do séc. XIX, acentuando-se durante o séc. XX.

Assim, em 1864 chegavam ao Rio de Janeiro 5.097 trabalhadores portugueses, enquanto que as estatísticas nada registram para São Paulo.

De 1865 à 1869 chegaram no Rio de Janeiro 24.102 imigrantes, ou seja, 99,3\%. Em São Paulo, chegaram 244 imigrantes, ou seja, 0,7\%.

Entretanto, é preciso dizer que, apesar do grande número de imigrantes portugueses no Rio de Janeiro de 1864 à 1873 - 66.258, somente 34,126 fixam-se nesta cidade, ou seja, 51,5\%. Os outros 32.132 imigrantes, ou seja, $48,5 \%$ se dispersaram para outras cidades do norte (Bahia, Manaus, etc.).

A atividade econômica mais importante que os imigrantes portugueses no Brasil procuravam, foi sem dúvida, o comércio e o setor de serviços ${ }^{24}$. Poucos se dirigiram para a lavoura em São Paulo. Daí que a imigração portuguesa no Brasil não pode ser vista como uma necessidade de atender ao desenvolvimento da agricultura cafeeira em substituição à mão-de-obra escrava.

O que motivou os portugueses no final do séc. XIX a emigrarem para o Brasil não corresponde, portanto, à nossa primeira necessidade de braços para a agricultura. Acreditamos, porém, que os imigrantes puderam contribuir mais no nosso desenvolvimento do setor secundário. De fato, durante o séc. XX são os portugueses o maior contingente de imigrantes que recebemos.

\section{Conclusão}

1. Vimos que a emigração portuguesa para o Brasil no final do séc. XIX é conseqüência da transição econômica e política por que passava Portugal naquele período.

2. A emigração, através das remessas, era o único recurso econômico para o governo português de equilibrar sua balança comercial. Apesar desta

23 Infelizmente, não dispomos de dados estatísticos para as atividades econômicas dos portugueses no Brasil.

24 Para 1930 temos notícias de que 1.795 portugueses trabalhavam na Light; 133, na Viaçåo Excelsior; 1.276, no Departamento de Tráfego e 275 na Cia. Jardim Botânico, tơlos no Rio de Janeiro. In : "O Estado de Sĩo Paulo", 19/12/1930. 
PASCKES, Maria Luisa Nabinger de Almeida. Notas sobre os imigrantes portugueses no Brasil (sécs. XIX e XX).

emigração ser desordenada no final do séc. XIX e início do séc. XX, ela concorreu, politicamente, também para diminuir as situações de conflito com o desenvolvimento das forças produtivas, sobretudo na agricultura.

3. Para o período de Salazar, a partir de 1933, observamos uma ligeira queda na emigração portuguesa para o Brasil. Por um lado, isto seria explicado pelo maior controle da emigração, sobretudo a partir do estabelecimento da política de emprego naquele país. Na verdade, esta política de emprego não deixou de estimular, indiretamente, a emigração. Por outro, houve mudanças nos destinos da emigração. Ao lado do Brasil, passam a figurar a Venezuela, os EUA, o Canadá e a Europa como novos caminhos da emigraçăo portuguesa.

4. As remessas dos imigrantes portugueses no Brasil eram a principal fonte de recursos para o governo português.

5. A maioria dos imigrantes portugueses, sobretudo no final do séc. XIX e início do séc. XX, desejavam "melhorar de fortuna". Daí, a razão pela qual se dirigiam para o Brasil, "terra de muitas riquezas", constituindo assim no país do "eldorado".

6. Do final do séc. XIX até 1960, a maioria dos imigrantes portugueses no Brasil, eram originários da parte do norte de Portugal. A destacar: Beira Alta, Beira Litoral, Douro Litoral, Trás-os-Montes, Minho e Estremadura, com oscilações de predominância entre estas regiões neste longo período.

7. A principal atividade econômica dos emigrantes portugueses era a agricultura, seguida pelo comércio, construção civil e outras atividades do setor secundário.

8. No Brasil, os imigrantes portugueses vão dedicar-se às atividades urbanas, entre elas o comércio, em detrimento da atividade agrícola.

9. O maior contingente imigratório localizava-se em primeiro lugar, no Distrito Federal, no Estado do Rio de Janeiro e outras cidades do norte do Brasil (Bahia, Manaus, etc.). Posteriormente, aumentará o fluxo imigratório para São Paulo.

10. Em São Paulo, os imigrantes portugueses continuarão dedicandose ao setor secundário.

11. A imigração portuguesa no Brasil foi trazida pela atração econômica que o país representava e não pela possibilidade de substituir-se a mão-de-obra escrava na agricultura.

12. No Brasil, os imigrantes portugueses participariam do desenvolvimento dos setores industrial e de serviços (o comércio), sobretudo a partir de 1930. 
R. Histórla, São Paulo, n. 123-124, p. 35-70, ago./ jul., 1990/1991.

ABSTRACT - The Portuguese immigration to Brazil at the end of the XIX ${ }^{\text {th }}$ Century was a consequence of this period's political and economical transition. The contigent "remittance" system was a resource used to satisfy double interests. One hand, it aliviated the tension caused by groups that wanted to leave Portugal; on the other hand, it facilitated internal stability. Under these circunstances, Brazil stuck out as the ideal place for immigration. Brazil being a rich country, in development and having Portuguese traditions, institutions, and language motivated those interested. 